Article

\title{
Trip Chaining Model with Classification and Optimization Parameters
}

\author{
Domokos Esztergár-Kiss (D) \\ Department of Transport Technology and Economics, Faculty of Transportation Engineering and Vehicle \\ Engineering, Budapest University of Technology and Economics (BME), 1111 Budapest, Hungary; \\ esztergar@mail.bme.hu
}

Received: 23 June 2020; Accepted: 6 August 2020; Published: 10 August 2020

\begin{abstract}
In order to model the complex requirements of users travelling in an urban environment, the relevant parameters for creating activity chains have to be identified. In this study, travel related parameters were collected and grouped into two main types: classification parameters and optimization parameters. In the case of optimization parameters, further grouping was performed where general and comfort parameters were introduced. Additionally, the possible values and data sources of the parameters were identified. A utility function was created to take into account the optimization parameters and the weights. Weights related to comfort optimization parameters were aggregated to decrease the number of required settings by the users. Finally, the features of the proposed optimization algorithm are described. With the identified parameters, aggregated weights and elaborated utility function activity chains can be optimized for users with different requirements.
\end{abstract}

Keywords: travel behavior; activity chains; classification; optimization; parameter definition

\section{Introduction}

Recent developments in the field of travel behavior are dealing with topics like activity-based trip analysis, mode choice modeling, travel demand management, and flexible mobility options. About 20 years ago, Bhat and Singh [1] developed an analytical framework to identify the travel patterns of workers by estimating the commuting mode choice, the number of stops, and arrival periods. In the same period, Wen and Koppelman [2] found empirical results to demonstrate the connection of individual parameters to activity location choice and tour formulation. Bowman and Ben-Akiva [3] presented a daily activity scheduling concept where activity and travel related decisions were handled together with transport mode, time choice, and activity location. Islam and Habib [4] investigated the effect of socio-demographic characteristics on activity chains and found that several characteristics played a major role in influencing trips. Many other aspects of activity chains have been studied such as the comparison of travel behavior by men and women by McGuckin and Murakami [5]; the analysis of activity chains in specific regions by Subbarao and Krishna Rao [6]; the assessment by age group by Golob and Hensher [7]; and travel patterns of specific user groups [8]. These papers highlight that activity-based modeling needs to include several types of parameters.

Mazzula [9] analyzed user responses by applying an activity-based approach, where stated preference and revealed preference results were combined. Random utility models were used to simulate travel behavior and potential choice alternatives. In order to define traveler profiles, Pronello and Camusso [10] used factor analysis and cluster analysis. The study showed how significant constraints such as necessity, time saving, and transport supply determine a behavioral change, while Prillwitz and Barr [11] tried to assess the role of attitudes for travel decisions. The results demonstrated the usefulness and limitations of segmentation approaches and underlined the need for more comprehensive mobility style frameworks. Haustein and Hunecke [12] worked on the creation of useful segmentations 
of travel groups who share similar attitudes and preferences. In their contribution, attitudinal, socio-demographic, geographical, and behavioral segmentations are compared to provide sustainable travel choices.

The research question arises, of how to define a suitable set of parameters and model the activity chain optimization with a utility function. Several researchers have dealt with aspects of trip chaining, activity scheduling, and travel behavior, where user related parameters and grouping options were also investigated. However, the representation of detailed user requirements in an activity chain optimization framework has not appeared as of yet. Therefore, in this paper, a model with a set of parameters and a utility function are introduced. Such a detailed description of trip chaining parameters and the related utility function with weights has not been realized, thus the contributions of this paper provide a real added value to the literature. With this achievement, it will be possible to create more advanced activity chains taking into account user requirements. The main contributions of this paper are:

- $\quad$ To provide a detailed classification of parameters related to trip chaining.

- To identify the types, potential values, and data sources of the parameters.

- To aggregate weights related to parameters, so that user settings can be easier.

- To create a utility function for the activity chain optimization.

The rest of this paper is structured as follows. Section 2 presents the literature review. In Section 3, the parameters are defined, which were separated into two groups: classification and optimization parameters. In Section 4, the model is elaborated, where the utility function connects with the weights and parameters. In Section 5, the implications, limitations, and realization options are discussed. Section 6 provides the conclusions.

\section{Literature Review}

Trip chaining, or often called activity chain optimization, has been investigated by Timmermans et al. [13], who described and analyzed travel patterns. They proved that travel patterns are, in general, independent from spatial settings. Liao et al. [14] modeled the activity-travel scheduling problem to predict short-term effects of travel information systems and travel demand management. The authors developed a multi-state supernetwork, where the temporal dimension was also included when selecting the locations of activities. More importantly, personal preferences were taken into account, which supported optimal solutions for the travelers. Buliung et al. [15] explored the spatial variety of activity patterns and highlighted the importance of the flexibility of activities; however, no algorithm was developed to provide solutions to the travelers. Balaji et al. [16] worked on a hybrid approach that combined customer prioritization with optimization algorithms. In their model, users were clustered, and optimal routes were assigned using the analytic hierarchy process (AHP). Hafezi et al. [17] developed a method for modeling the daily activity patterns of individuals. The dependencies between activity type, activity frequency, and socio-demographic characteristics were taken into account while employing a random forest model. Kang and Recker [18] proposed an algorithm for daily activity scheduling using the location selection problem, where the locations of activities were chosen using predetermined and alternative locations. In order to define the best solutions, a utility function was introduced. The problem of huge search space was in this case solved with dynamic programming. Hilgert et al. [19] developed a mobility assistance system that gathers information from timetables and a real time information system. Furthermore, it knows the user plans and can reorganize weekly activity schedules according to personal preferences. They included both personal and network related parameters. In order to collect data from activities and user preferences, traditional survey methods and automatic data collection methods can be applied $[20,21]$. The answers of the questionnaires can be analyzed by AHP in order to determine the preferences of user groups [22]. However, these methods require time and human resources. A current application for automatic data collection is GTPlanner [23], 
which takes into account personal preferences when planning routes for users, and also provides information on their trips.

Lawton [24] claimed that there were four possible sources of information to build up or feed activity-based models, which may be used to identify parameters of an optimization model: household surveys (revealed preference) to study activities that influence travel demand; stated response surveys to investigate activity-travel patterns; longitudinal panel surveys; and retrospective surveys of activities to explore long term behavior (e.g., household location decisions). The combination of these methods with information technology supported information may help to identify personal parameters to establish a proper activity chain optimization model. In connection with this, an important aspect of a survey by Frignani [25] was the attempt to capture activity-travel planning attributes. The planning attributes were focused on timing and the constraints of planning decisions and explored whether user decisions regarding transportation mode are mainly driven by routine, while the choice of start time of activities is more individual and impulsive. In addition, Artenze et al. [26] developed a latent-class user model for tourists, where they used activity location-based parameters and trip-based parameters (i.e., tourist attraction values, time-use characteristics and point of interest (POI) attributes). With a multi-attribute utility function, personalized optimal tours were offered for the users. This approach was also utilized in the current research.

Relevant papers were collected (Table 1), which cover the aspects of activity chain optimization, especially the general goal setting (modeling, with algorithm development), the used network (multimodal, with activity types), the applied calculation method (optimization, with utility function), and the types of parameters included (classification, with optimization parameters).

Table 1. Comparison of related papers.

\begin{tabular}{|c|c|c|c|c|c|c|c|c|c|}
\hline Author & Topic & 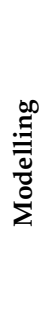 & 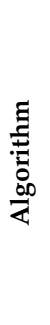 & 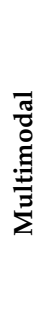 & 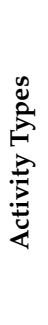 & 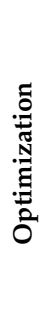 & 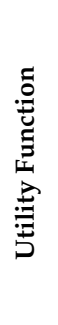 & 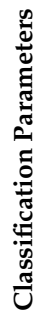 & 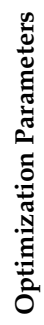 \\
\hline Artenze (2013) [27] & $\begin{array}{l}\text { Personalized advice based } \\
\text { on travel choices }\end{array}$ & $x$ & & $\mathrm{x}$ & & & & $\mathrm{x}$ & \\
\hline Nijland et al. (2012) [28] & $\begin{array}{l}\text { Effects of planned activities } \\
\text { on the activity schedule }\end{array}$ & $\mathrm{x}$ & & & & & & $\mathrm{x}$ & \\
\hline Miller and Roorda (2003) [29] & $\begin{array}{l}\text { Activity schedules and } \\
\text { travel patterns }\end{array}$ & $\mathrm{x}$ & & & & $x$ & & & \\
\hline Chowdhury and Scott (2020) [30] & $\begin{array}{l}\text { Built environment with } \\
\text { personal parameters }\end{array}$ & $\mathrm{x}$ & & $\mathrm{x}$ & & & & $\mathrm{x}$ & \\
\hline Dib et al. (2015) [31] & $\begin{array}{l}\text { Route planning using } \\
\text { genetic algorithm }\end{array}$ & $\mathrm{x}$ & $\mathrm{x}$ & $\mathrm{x}$ & & $\mathrm{x}$ & & & \\
\hline Ghiani (2011) [32] & $\begin{array}{l}\text { Traveling Salesman Problem } \\
\text { with heuristic algorithm }\end{array}$ & $\mathrm{x}$ & $\mathrm{x}$ & & & $\mathrm{x}$ & & & \\
\hline Nuzzolo and Comi (2016) [33] & $\begin{array}{l}\text { Route suggestions based on } \\
\text { individual utility function }\end{array}$ & $\mathrm{x}$ & $x$ & $\mathrm{x}$ & & $\mathrm{x}$ & $\mathrm{x}$ & & \\
\hline Västberg et al. (2019) [34] & $\begin{array}{l}\text { Dynamic activity } \\
\text { travel planning }\end{array}$ & $x$ & $\mathrm{x}$ & $\mathrm{x}$ & $\mathrm{x}$ & $\mathrm{x}$ & $\mathrm{x}$ & & \\
\hline Pougala et al. (2020) [35] & Scheduling of daily activities & $x$ & $x$ & $\mathrm{x}$ & $\mathrm{x}$ & $x$ & $x$ & & \\
\hline Malik and Kim (2019) [36] & $\begin{array}{l}\text { Optimal Travel Route } \\
\text { Recommendation }\end{array}$ & $\mathrm{x}$ & $\mathrm{x}$ & & & $x$ & $\mathrm{x}$ & $\mathrm{x}$ & $\mathrm{x}$ \\
\hline Charypar and Nagel (2005) [37] & $\begin{array}{l}\text { Scheduling with multi-agent } \\
\text { simulation model }\end{array}$ & $\mathrm{x}$ & $\mathrm{x}$ & & & $x$ & $\mathrm{x}$ & $\mathrm{x}$ & $\mathrm{x}$ \\
\hline proposed & Activity chain optimization & $\mathrm{x}$ & $x$ & $\mathrm{x}$ & $\mathrm{x}$ & $\mathrm{x}$ & $x$ & $x$ & $x$ \\
\hline
\end{tabular}


Artenze [27] placed emphasis on providing personalized advice for travelers. The main idea was to find out travel parameters based on choices, where empirical testing was performed based on a travel choice experiment; however, no optimization was performed. Nijland et al. [28] developed an activity-based model, where daily agendas were modeled based on a web survey with reported activities. The research analyzed the effects of planned activities on the decision to schedule an activity, but no optimization was realized. Another activity travel scheduling model was created by Miller and Roorda [29] based on travel diaries. Their aim was to understand the process of how travelers schedule and reschedule activities with a utility maximization approach, however, several features were lacking such as flexibility and multimodality. Chowdhury and Scott [30] examined the influence of the built environment on trip-chaining behavior with regression models. They took into account personal and household characteristics, and a few attitudinal variables, but did not use detailed optimization parameters. Their focus was rather on the modeling of accessibility, and not on the optimization of trips during the day using a utility function, which is present in our model.

Dib et al. [31] worked on a route planning problem in a practical way. They developed route planning methods in multimodal transportation networks using genetic algorithms and variable neighborhood search methods. In contrast to traditional algorithms, this approach was fast enough for practical routing applications. However, the approach was presented on a theoretical network and did not consider daily activities and optimization parameters. Ghiani et al. [32] solved the traveling salesman problem with heuristic algorithms to generate optimal activity chains. Here, the implementation of daily activity optimization was presented, however, neither flexibility nor a complex utility function were elaborated. Nuzzolo and Comi [33] created a method of how to choose paths in multimodal travel networks. The method used an individual traveler utility function, which allowed personal preferences to be included, although daily activity chains and complex optimization parameters were not considered.

Västberg et al. [34] developed a dynamic discrete choice model for daily activity travel planning including individual preferences and generating a utility function. Additionally, time-space constraints were taken into account, but personal and optimization parameters were not. One of the most complex solutions was provided by Pougala et al. [35], who elaborated a scheduling method for daily activities where a complex utility function with flexible activities was included using a mixed integer programming approach. They covered four transportation modes and 11 activity types; however, classification parameters were not considered.

Malik and Kim [36] created an optimal travel route recommendation mechanism to predict the best routes for tourists based on neural networks and particle swarm optimization. In their route optimization, a complex utility function was created, and five main optimization factors were included; however, activity types did not play a role, and only a limited number of optimization parameters were considered. Another excellent approach was elaborated by Charypar and Nagel [37], who applied genetic algorithm to provide activity plans, where a complex utility function was created taking into account the preferences of the users. Their utility function included the time and the location of the activity, however, multimodality and activity types were not handled.

\section{Definition of Classification and Optimization Parameters}

In order to model the complex requirements of users regarding an urban activity chain, the possible optimization parameters were identified. In the literature, the main typical optimization parameters are time, cost, and comfort. Furthermore, the parameter type, component type, possible values, and data sources were created for grouping the parameters.

\section{Parameter Type:}

Two types of parameters can be introduced (Figure 1). The parameter type describes whether the parameter is a classification parameter or an optimization parameter. The detailed descriptions of the parameters follow the order of the parameter types, which are actually strongly linked to the component type. 


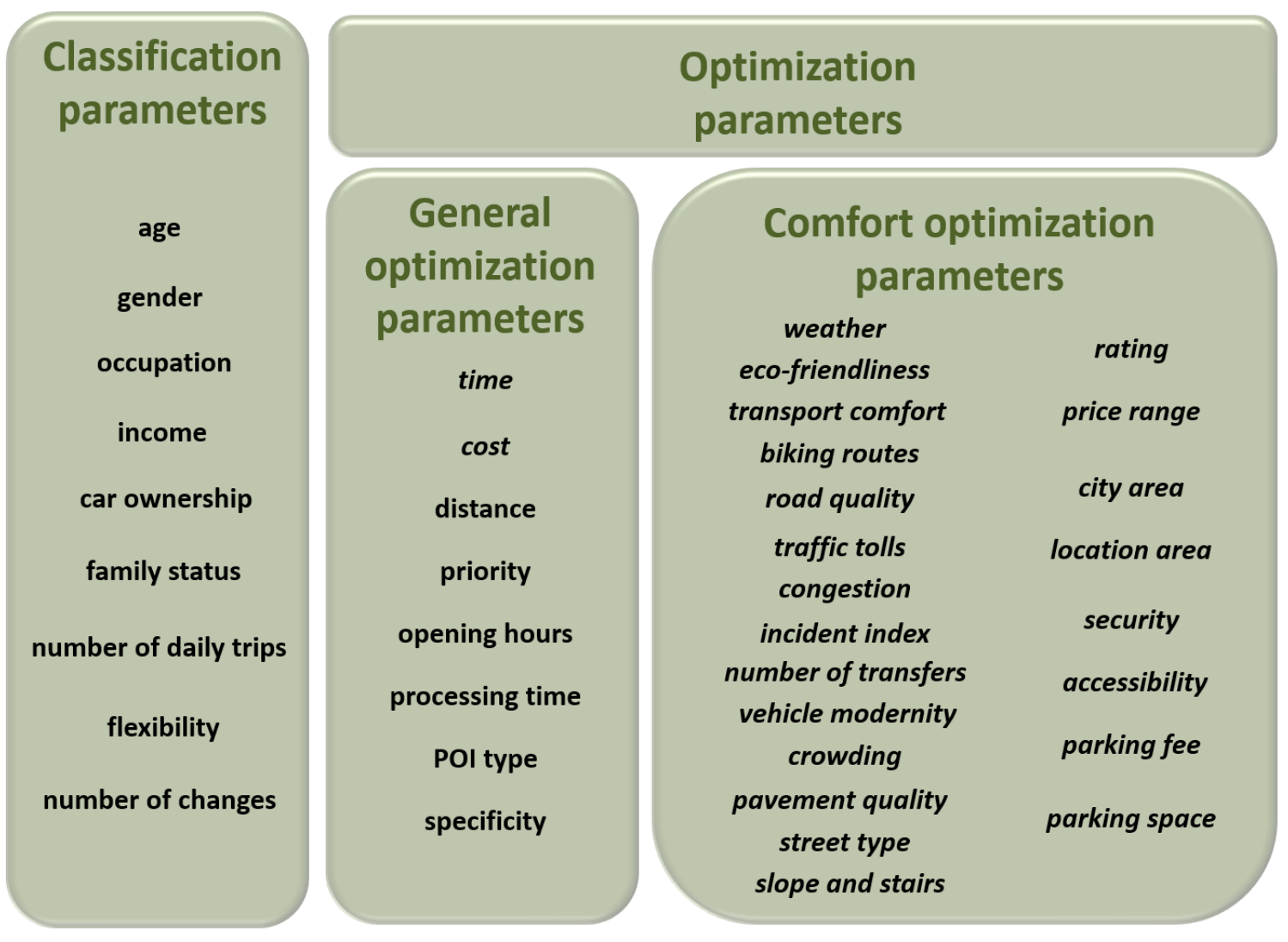

Figure 1. Grouping of parameters by parameter type.

The classification parameters are not used directly in the optimization process, but are crucial inputs for the classification of users into user groups. The creation of user groups facilitates user decisions about setting the weights for the optimization parameters. The user groups possess predefined settings of the weights, where the weights provide only an initial setting and the values can be changed by personal preferences.

The optimization parameters are used in the optimization process. Their two main groups are the general optimization parameters without weights (with exception of time and cost) and the comfort optimization parameters with weights. Usually, general optimization parameters are parameters with fixed or predefined values, where weighting cannot be defined (e.g., opening times). Parameters present directly in the utility function are in italics.

\section{Component Type:}

Three types of component were identified: the user, the trip, and the location (Figure 2). Most parameters clearly belonged to one component type, but some parameters influenced more component types, therefore they were placed in the intersections. The user includes classification and optimization parameters, which depend on the individual user. The trip contains optimization parameters and is divided into sub-types according to the transportation modes, as transportation modes have specific parameters. The location consists of those optimization parameters, which are connected to the location of the activity.

\section{Possible Values:}

In the case of optimization parameters with numeric values, the quantification and creation of categories is easy, as exact values can be assigned to the categories (e.g., prices). The quantification is also possible for optimization parameters with a textual value set by assigning artificially created value categories. In some cases, the optimization parameters can only be categorized by applying heuristic considerations or the exact values of the categories can be learned by collecting a large number of examples (e.g., crowding). In the case of optimization parameters with weights, the parameters have 
the following possible values: low, medium, high. Low values represent "good" features, while high values represent "bad" features.

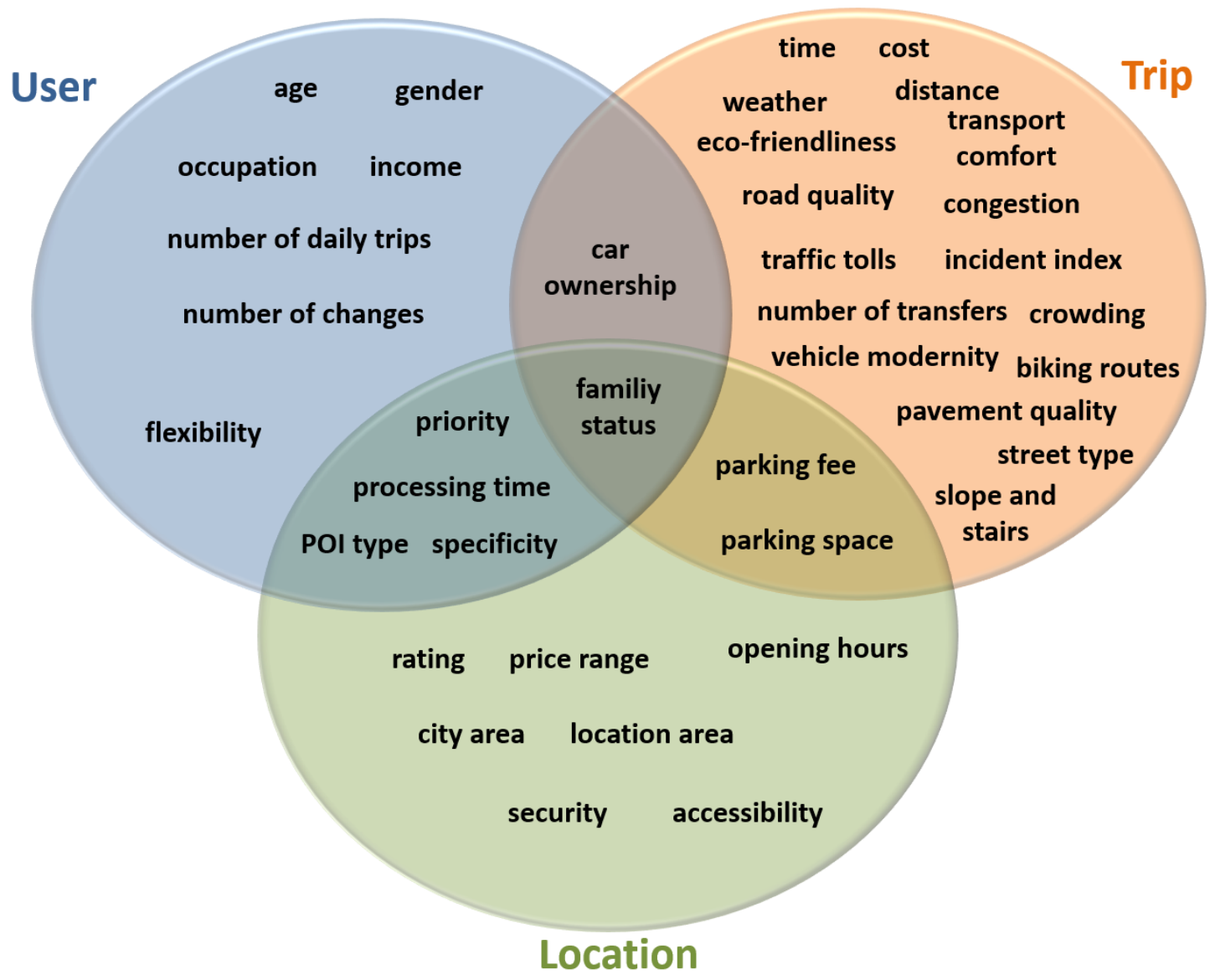

Figure 2. Identification of parameters by component type.

\section{Data source:}

The data source refers to the origin of the parameters, which can originate from the user (by setting the requested values), from the application (by collecting and evaluating usage statistics), or from external sources (by receiving data or datasets). The external sources can be represented by a transport operator, a municipality, a social media provider, a POI database, or other databases.

\subsection{Classification Parameters}

In the following section, the parameters are grouped by the parameter type. The comfort optimization parameters are further divided by the component type.

The classification parameters and their attributes are identified in Table 2, and are mainly connected to the user component type.

- Age, gender, occupation, income, car ownership, family status: The basic socio-economic data, which are required to categorize users into user groups.

- Number of daily trips: Average number of trips during a day (e.g., users with family tend to make more daily trips, while pensioners probably make fewer daily trips).

- Flexibility: Average number of flexible activities during a day (e.g., users with flexible working hours and students tend to have more flexible activities).

- Number of changes: Average number of changes in daily activity plans (e.g., younger people tend to change their mind and have new unplanned events during the day). 
Table 2. Description of classification parameters.

\begin{tabular}{|c|c|c|c|c|}
\hline & Parameter Type & Component Type & Values & Data Source \\
\hline age & classification & user & $\begin{array}{c}1(0-20) \\
2(21-30) \\
3(31-40) \\
4(40-60) \\
5 \text { (more than 60) }\end{array}$ & user \\
\hline gender & classification & user & $\begin{array}{c}1 \text { (male) } \\
2 \text { (female) }\end{array}$ & user \\
\hline occupation & classification & user & $\begin{array}{c}1 \text { (student) } \\
2 \text { (worker) } \\
3 \text { (pensioner) }\end{array}$ & user \\
\hline income & classification & user & $\begin{array}{c}1(0-500) \\
2(500-1000) \\
3(1000-2000) \\
4(2000-3000) \\
5 \text { (more than } 3000 \text { Euro) }\end{array}$ & user \\
\hline car ownership & classification & user/trip & $\begin{array}{c}1 \text { (no car) } \\
2 \text { (one car) } \\
3 \text { (more cars) }\end{array}$ & user \\
\hline family status & classification & user/trip/location & $\begin{array}{c}1 \text { (single) } \\
2 \text { (married) } \\
3 \text { (has children) }\end{array}$ & user \\
\hline number of daily trips & classification & user & $\begin{array}{c}1(0-1) \\
2(2-3) \\
3 \text { (more than 3) }\end{array}$ & user/application \\
\hline flexibility & classification & user & $\begin{array}{c}1(0-1) \\
2(2-3) \\
3 \text { (more than } 3)\end{array}$ & user/application \\
\hline number of changes & classification & user & $\begin{array}{c}1(0-1) \\
2(2-3) \\
3 \text { (more than } 3 \text { ) }\end{array}$ & user/application \\
\hline
\end{tabular}

\subsection{General Optimization Parameters}

The general optimization parameters were identified. Most of these parameters were without weights, with the exception of time and cost. These parameters are mainly connected to both the user and the location component type (Table 3).

Table 3. Description of the general optimization parameters.

\begin{tabular}{|c|c|c|c|c|}
\hline & Parameter Type & Component Type & Values & Data Source \\
\hline time & with weight & trip & $0-1000 \mathrm{~min}$ & $\begin{array}{l}\text { map provider/ } \\
\text { transport operator }\end{array}$ \\
\hline cost & with weight & trip & 0-1000 Euro & $\begin{array}{l}\text { map provider/ } \\
\text { transport operator }\end{array}$ \\
\hline distance & without weight & trip & $\begin{array}{l}0-10.000 \mathrm{~m} \\
1 \text { (fix) }\end{array}$ & map provider \\
\hline priority & without weight & user/location & $\begin{array}{c}2 \text { (temporally flexible) } \\
3 \text { (spatially flexible) } \\
4 \text { (totally flexible) }\end{array}$ & user \\
\hline opening hours & without weight & location & $0-24 \mathrm{~h}$ & POI database \\
\hline processing time & without weight & user/location & 0-1000 min & user \\
\hline POI type & without weight & user/location & $\begin{array}{l}\text { several types (e.g., restaurant, } \\
\text { post office) }\end{array}$ & user/POI database \\
\hline specificity & without weight & user/location & special brands under POI type & user/POI database \\
\hline
\end{tabular}

- Time (p1): Total travel time spent during a trip (e.g., driving time is calculated from the distance, public transport time is calculated from the timetable information). 
- Cost (p2): Price to be paid for the chosen trip for different transportation modes (e.g., driving cost is calculated from the distance, public transport cost is calculated from the number of needed tickets).

- Distance (p3): Defines locations and distances, so that trip times can be calculated.

- Priority ( $\mathrm{p} 4)$ : The priority of the actual activity that can be processed in the given location (e.g., fix or flexible).

- Opening hours (p5): Time interval between the opening time and closing time of the given location.

- Processing time (p6): Time spent by the user at the given location [minutes].

- POI type (p7): The type of the location regarding the point of interest typology (e.g., restaurant, post office).

- Specificity (p8): Defines whether one brand is searched by the user or more brands of the same POI type are possible solutions.

\subsection{Comfort Optimization Parameters}

The comfort optimization parameters were described connected to the trip component type (Table 4).

- Weather (p9): Measure for the actual daily average weather situation measured by the temperature and the humidity (e.g., rainy, windy).

- Eco-friendliness (p10): Measure for environmental classification of different transportation modes measured by their average $\mathrm{CO}_{2}$ emission (e.g., biking is very eco-friendly as it produces no emissions).

- Transport comfort (p11): Measure for the comfort level generally provided by transportation modes measured by social norms (e.g., cars considered comfortable).

- Biking routes (p12): Type of roads used by bikers, if during a trip more types are present, then their average value regarding the length has to be taken into account.

- Road quality (p13): Measure for the quality of roads.

- Traffic tolls (p14): Average price to be paid on certain roads.

- Congestion (p15): Average percentage of congestion on a certain trip during a day.

- Incidents index (p16): Number of yearly incidents along a chosen trip per average hourly traffic volume.

- Number of transfers (p17): Number of transfers between two consecutive activities.

- Vehicle modernity (p18): Age of the used vehicle during a trip.

- Crowding (p19): Percentage of passengers per capacity in the vehicle.

- Pavement quality (p20): Measure for the quality of pavements.

- Street type (p21): Type of streets (e.g., main road, park, alley).

- Slope and stairs (p22): Measure for the steepness of the streets and existence of stairs during the trip (e.g., locations in hilly areas are harder to access for elderly people).

Finally, comfort optimization parameters were identified connected to the location component type (Table 5).

- $\quad$ Rating (p23): Average value calculated from reviews of the location by other users.

- Price range (p24): Average prices of typical services in the given location.

- City area (p25): Type of the far environment (e.g., district), where the place is located.

- Location area (p26): Type of the close environment (e.g., main road, park, alley).

- Security (p27): Number of yearly crimes in the city area, where the place is located.

- Accessibility (p28): Measure for the easiness to access the location (with wheelchair).

- Parking fees (p29): Average price of parking fees in the area of the location.

- Parking space (p30): Number of free parking spaces in the area of the location. 
Table 4. Description of comfort optimization parameters of trip component type.

\begin{tabular}{|c|c|c|c|c|c|c|}
\hline & Parameter Type & Component Type & Low Value & Middle Value & High Value & Data Source \\
\hline weather & biking, car, PT habits & trip & good weather & windy, rainy, cold & heavy rain or snow & meteorology \\
\hline eco-friendliness & lifestyle & trip & biking, walking & public transport & car & operator/ municipality \\
\hline transport comfort & social status & trip & car & public transport & biking, walking & society \\
\hline biking routes & biking habits & trip (bike) & bike lane & average road & off-road & municipality \\
\hline road quality & biking, car habits & trip (car) & perfect & average & bad & road network operator \\
\hline traffic tolls & price sensitivity & trip (car) & 0-1 Euro & 2-3 Euro & more than 3 Euro & road network operator \\
\hline congestion & delay sensitivity & trip (car) & free flow & normal traffic & congested & traffic information \\
\hline incident index & delay sensitivity & trip (car) & $0-0,1$ & $0.2-0.3$ & more than 0.3 & national office \\
\hline number of transfers & PT habits & trip $(\mathrm{PT})$ & $0-1$ & $2-3$ & more than 3 & transport operator \\
\hline vehicle modernity & PT habits & trip $(\mathrm{PT})$ & $0-5$ & $6-10$ & more than 10 years old & transport operator \\
\hline crowding & PT habits & trip $(\mathrm{PT})$ & $0-30 \%$ & $31-60 \%$ & $61-100 \%$ & transport operator \\
\hline pavement quality & walking habits & trip (walking) & perfect & average & bad & road network operator \\
\hline street type & walking habits & trip (walking) & alley, park & street, avenue & highway, main street & municipality \\
\hline slope and stairs & special needs & trip (walking) & straight & hilly & steep or many stairs & municipality \\
\hline
\end{tabular}

Table 5. Description of comfort optimization parameters of location component type.

\begin{tabular}{|c|c|c|c|c|c|c|}
\hline & Parameter Type & Component Type & Low Value & Middle Value & High Value & Data Source \\
\hline rating & area sensitivity & location & $4-5$ & 3 & $1-2$ & social media \\
\hline price range & social status & location & $4-5$ & 3 & $1-2$ & social media \\
\hline city area & area sensitivity & location & city center & suburbs & industrial area & municipality \\
\hline location area & area sensitivity & location & alley, park & street, avenue & highway, main street & municipality \\
\hline security & lifestyle & location & $0-10$ & $10-30$ & more than 30 crimes & national office \\
\hline accessibility & special needs & location & fully accessible & difficultly accessible & not accessible & POI database \\
\hline parking fees & price sensitivity & location & $0-1$ & $2-3$ & more than 3 Euro & road network operator \\
\hline parking space & social status & location & $0-10$ & $11-20$ & more than 20 spaces & traffic information \\
\hline
\end{tabular}




\section{Elaboration of the Method}

Utility functions were introduced in order to combine the values of the optimization parameters and to support the creation of activity chains. The utility functions consist of optimization parameters and weights. Weights related to comfort optimization parameters are aggregated weights.

\subsection{Aggregated Weights}

The aggregated weights were introduced to decrease the number of required settings by the users. They influence the relevance of more optimization parameters, thus the modeling of typical user requirements is present. The possible values of the aggregated weights can be between one and five. These values are predefined by the user groups (average values), but can be changed by the user (Figure 3). The utility functions $(\mathrm{u}(\mathrm{p}, \mathrm{w}))$ regarding comfort optimization parameters were formalized, creating the mathematical context of dependencies between optimization parameters and aggregated weights. The following aggregated weights were defined:

- Routine $\left(\mathrm{w}_{\mathrm{r}}\right)$ : Measure of willingness to differ from well-known routes; this weight has a general effect on several parameters (e.g., willingness to make detours, if it is beneficial), is a super aggregation with an effect on delay sensitivity, lifestyle, quality sensitivity, price sensitivity, and area sensitivity.

- Delay sensitivity $\left(\mathrm{w}_{1}\right)$ : Average delay tolerated by the user, which depends on the congestion and the incident probability of the chosen trip (e.g., users with high delay sensitivity should avoid congested routes).

$$
\mathrm{u}_{1}(\mathrm{p}, \mathrm{w})=\left(\mathrm{p}_{15} * \mathrm{w}_{1}+\mathrm{p}_{16} * \mathrm{w}_{1}\right) * \mathrm{w}_{\mathrm{r}}
$$

- $\quad$ Lifestyle $\left(\mathrm{w}_{2}\right)$ : Measure for environmental consciousness and security features (e.g., rather using more eco-friendly transportation modes and avoiding dangerous areas).

$$
\mathrm{u}_{2}(\mathrm{p}, \mathrm{w})=\left(\mathrm{p}_{10} * \mathrm{w}_{2}+\mathrm{p}_{27} * \mathrm{w}_{2}\right) * \mathrm{w}_{\mathrm{r}}
$$

- Quality sensitivity $\left(\mathrm{w}_{3}\right)$ : Measure for taking comfort features, price ranges, and parking space into account (e.g., businessmen tend to use cars and visit places with higher prices).

$$
\mathrm{u}_{3}(\mathrm{p}, \mathrm{w})=\left(\mathrm{p}_{11} * \mathrm{w}_{3}+\mathrm{p}_{30} * \mathrm{w}_{3}+\mathrm{p}_{24} * \mathrm{w}_{3}\right) * \mathrm{w}_{\mathrm{r}}
$$

- Price sensitivity $\left(\mathrm{w}_{4}\right)$ : Willingness to pay for a certain trip, which includes traffic tolls and parking fees (e.g., workers may travel longer distances, where no traffic toll has to be paid).

$$
\mathrm{u}_{4}(\mathrm{p}, \mathrm{w})=\left(\mathrm{p}_{14} * \mathrm{w}_{4}+\mathrm{p}_{29} * \mathrm{w}_{4}\right) * \mathrm{w}_{\mathrm{r}}
$$

- Area sensitivity $\left(\mathrm{w}_{5}\right)$ : Measure for taking features regarding ratings and the area of the location into account such as the city area and location area (e.g., users tend to visit restaurants in the city center, but a recreational activity rather close to a park).

$$
\mathrm{u}_{5}(\mathrm{p}, \mathrm{w})=\left(\mathrm{p}_{26} * \mathrm{w}_{5}+\mathrm{p}_{23} * \mathrm{w}_{5}+\mathrm{p}_{25} * \mathrm{w}_{5}\right) * \mathrm{w}_{\mathrm{r}}
$$

- $\quad$ Biking preference $\left(\mathrm{w}_{\mathrm{b}}\right)$ : Measure of the willingness of using a bike during trips (e.g., students tend to bike more often); this weight has a general effect on biking related parameters,

- Biking habits $\left(\mathrm{w}_{6}\right)$ : requirements of the users regarding road quality, biking routes, and weather (e.g., many users prefer built roads and good weather).

$$
\mathrm{u}_{6}(\mathrm{p}, \mathrm{w})=\left(\mathrm{p}_{12} * \mathrm{w}_{6}+\mathrm{p}_{13} * \mathrm{w}_{6}+\mathrm{p}_{9} * \mathrm{w}_{6}\right) * \mathrm{w}_{\mathrm{b}}
$$

- Car preference $\left(\mathrm{w}_{\mathrm{c}}\right)$ : Measure of the willingness of using a car during trips (e.g., businessmen tend to use their own cars more often); this weight has a general effect on car related parameters. 
- Car habits $\left(\mathrm{w}_{7}\right)$ : Requirements of the users regarding road quality and weather (e.g., certain users do not use their cars in winter).

$$
\mathrm{u}_{7}(\mathrm{p}, \mathrm{w})=\left(\mathrm{p}_{13} * \mathrm{w}_{7}+\mathrm{p}_{9} * \mathrm{w}_{7}\right) * \mathrm{w}_{\mathrm{c}}
$$

- $\quad$ PT preference $\left(w_{p}\right)$ : Measure of the willingness of using PT during trips (e.g., younger people prefer public transportation, because they can utilize their time more efficiently by reading on the vehicles); this weight has a general effect on PT related parameters.

- PT habits $\left(\mathrm{w}_{8}\right)$ : Requirements of the users regarding number of transfers, crowding, and vehicle types including cleanliness, comfortable seats, heating and air conditioning (e.g., users do not prefer old vehicles without air conditioning during the summer).

$$
\mathrm{u}_{8}(\mathrm{p}, \mathrm{w})=\left(\mathrm{p}_{17} * \mathrm{w}_{8}+\mathrm{p}_{19} * \mathrm{w}_{8}+\mathrm{p}_{18} * \mathrm{w}_{8}\right) * \mathrm{w}_{\mathrm{p}}
$$

- Walking preference $\left(\mathrm{w}_{\mathrm{w}}\right)$ : Measure of the willingness to walk during trips (e.g., young people tend to walk more); this weight has a general effect on walking related parameters.

- Walking habits $\left(\mathrm{w}_{9}\right)$ : Requirements of users regarding pavement quality, street type, and weather (e.g., certain users prefer nice road with trees and good weather).

$$
\mathrm{u}_{9}(\mathrm{p}, \mathrm{w})=\left(\mathrm{p}_{9} * \mathrm{w}_{9}+\mathrm{p}_{21} * \mathrm{w}_{9}+\mathrm{p}_{20} * \mathrm{w}_{9}\right) * \mathrm{w}_{\mathrm{w}}
$$

- Special needs $\left(\mathrm{w}_{10}\right)$ : The need for special services such as modern low floor vehicles, need to avoid stairs or slopes and accessibility of locations (e.g., users with wheelchairs do not like to visit places without ramps).

$$
\mathrm{u}_{10}(\mathrm{p}, \mathrm{w})=\mathrm{p}_{22} * \mathrm{w}_{10}+\mathrm{p}_{18} * \mathrm{w}_{10}+\mathrm{p}_{28} * \mathrm{w}_{10}
$$

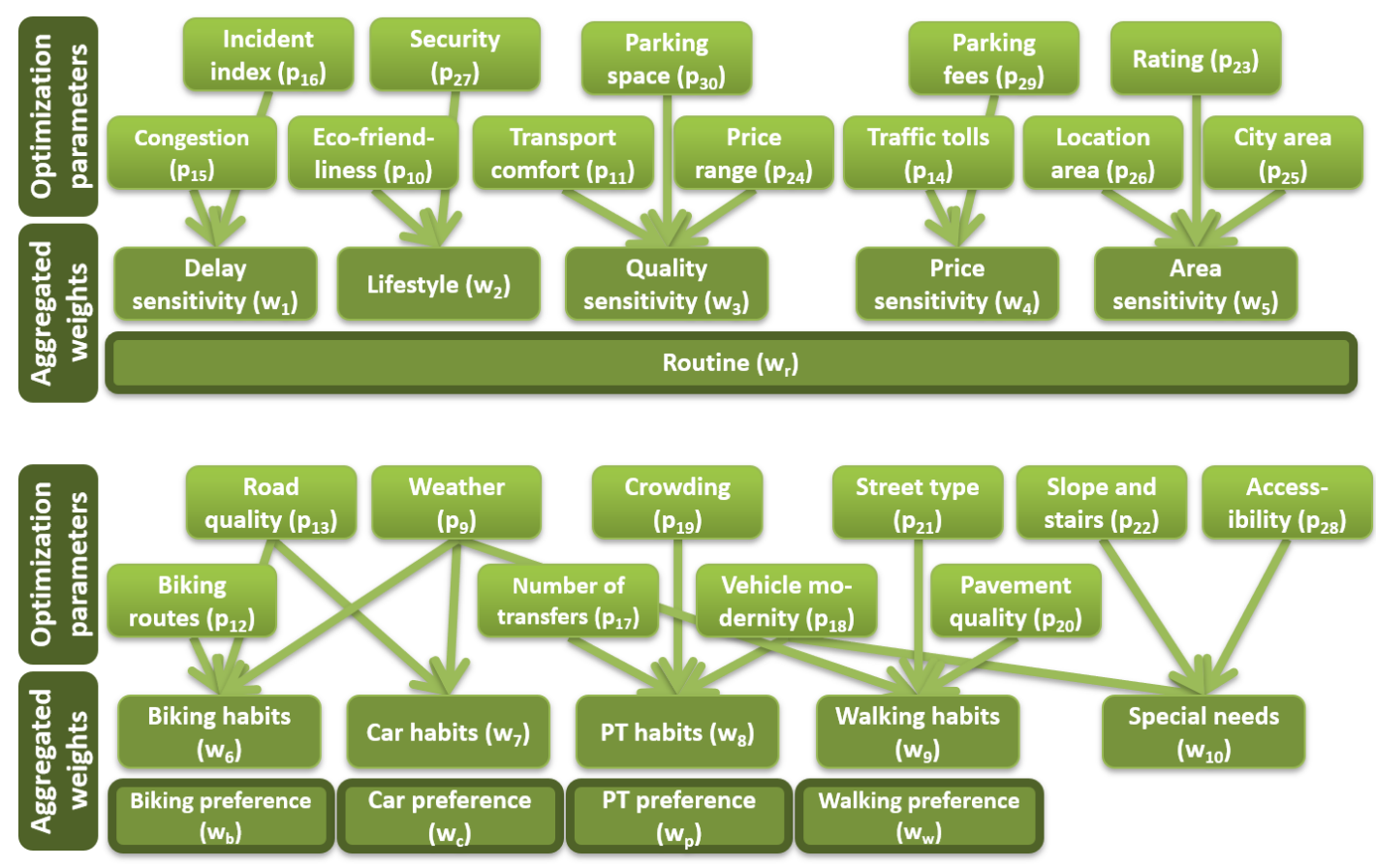

Figure 3. Aggregated weights and related optimization parameters.

\subsection{Utility Function}

The main utility function was defined as the sum of the products of optimization parameters and weights. The optimization parameters were weighted, where weights represent the personal 
preferences of the users. In the case of comfort optimization parameters, the weights were grouped into aggregated weights, so that users could express their requirements. The optimization parameters were values retrieved from external data sources, whereas weights and aggregated weights were set by the user. The value of time, the cost, and the value of comfort were different between user groups. During the optimization, the utility function is minimized. The minimization of time and cost is a well-known operation. In the case of comfort parameters, the possible values were defined in such a way that low values represent ideal conditions and high values represent not preferred conditions.

$$
\min \mathrm{u}(\mathrm{p}, \mathrm{w})=\mathrm{p}_{\text {time }} * \mathrm{w}_{\text {time }}+\mathrm{p}_{\text {cost }} * \mathrm{w}_{\cos \mathrm{t}}+\sum_{\mathrm{i}=1}^{\mathrm{m}} \mathrm{u}_{\mathrm{i}}(\mathrm{p}, \mathrm{w})
$$

- $\quad \mathrm{p}$-Optimization parameters.

- $\quad \mathrm{w}$-Weights (including aggregated weights).

- $\mathrm{u}(\mathrm{p}, \mathrm{w})-$ Main utility function.

- $p_{\text {time}}$-Value of time optimization parameter.

- $\mathrm{W}_{\text {time}}-$ Weight of time optimization parameter.

- $p_{\text {cost }}$-Value of cost optimization parameter.

- $\mathrm{w}_{\text {cost }}$-Weight of cost optimization parameter.

- $\quad \mathrm{u}_{\mathrm{i}}(\mathrm{p}, \mathrm{w})$-Utility function regarding comfort optimization parameters, $\mathrm{i}=1, \ldots, \mathrm{m}$.

- $\mathrm{m}-$ Number of utility functions regarding comfort optimization parameters.

\subsection{Optimization Algorithm}

The utility function supports the creation of the optimization algorithm. In general, optimization algorithms can be divided into two basic categories. The first type is exact algorithms [38,39], which search the whole solution space and provide a globally optimal solution, however, in most cases with considerably more processing time. The second type is heuristic algorithms, which use specific rules to speed-up the solution. This implies that not the whole solution space is searched, thus they usually provide only a nearly optimal solution. However, with proper settings, it is acceptable for practical applications [40].

For the optimization of activity chains, a special heuristic algorithm is to be applied. In the case of transportation related problems, the GA framework has been successfully applied to activity scheduling problems [41], such as the travelling salesman problem (TSP) [42], the travelling salesman problem with time-windows (TSP-TW) 42, and the vehicle routing problem (VRP) [43], which are classified as NP-hard problems [44]. These kinds of problems are usually harder to solve as the size of the network grows, however, when using the GA framework, solutions can be calculated in a reasonable amount of time.

The optimization algorithm uses this GA framework that iteratively solves the TSP-TW problem for different combinations. Thus, it provides a set of possible solutions, which are evaluated based on the elaborated utility function. After running the algorithm for several iterations, a nearly optimal solution can be derived for the planned activity chain of the user.

The functioning of the algorithm can be described in the following steps:

- Data input: This part is especially supported by the classification and optimization parameters, which were discussed in detail in Section 3. They provide the main input for the optimization algorithm. During the creation of activity chains, it is assumed that the user is already aware of the activities and other parameters, which are provided to the algorithm in advance.

- Creation of alternatives: Priority is one of the most important optimization parameters. Based on its value, if an activity is flexible, then the demanded service may be available in more places. The algorithm has to find these alternative locations, so that better alternatives can replace the original activity locations. However, if an activity is fixed, then the activity location cannot be changed and thus optimization cannot be performed for this activity. 
- Calculation of the utility function: With the original and alternative locations of activities, the utilities between the activity locations can be calculated. The utility function was discussed in detail in Sections 4.1 and 4.2, which provides the ranking of different alternatives.

- Optimization algorithm: The GA calculates based on the provided utility function of the best scenarios, which results in an optimized set of activity locations based on the provided classification and optimization parameters. The GA framework runs several times to find possible solutions. It is not ensured that the global optimum will be reached, however, with good parameter settings, the solution can be quite close.

- Visualization: The proposed activity chain has to be shown on a map, where the optimal activity locations are present, and the daily route is available.

\section{Discussion}

In this study, a well-defined utility function was created to support the optimization of activity chains. The main limitation of the study is the lack of realization, which will be done in a later stage of the research, however some considerations are discussed in this section.

A crucial point of the development of the planned algorithm is the specific setting of the GA framework, where the genetic operators have to be initiated, which are the selection, the mutation, and the crossover operators. Moreover, parameters of the GA framework also have to be set, which are the population size, the mutation probability, the crossover probability, and the number of generations. The exact realization of these steps requires an extensive analysis and testing of the proposed framework, which are part of the future research directions.

When realizing the optimization algorithm with the proposed utility function, a series of experiments need to be conducted to analyze the effectiveness of the algorithm. Thus, comparisons between the heuristic and the optimal solutions will be provided. In addition, a sensitivity analysis is needed to check how the setting of each parameter changes the results of the optimization.

The application of the utility function could be used in any preferred location where the following data are available: a map of the city with routes provided by a map operator, the timetable of public transportation provided by the transport operator through an interface, city specific parameters provided by local authorities, and the set of activities provided by the travelers. In case some data are not present, the algorithm would be still functional, however, the optimum would be calculated by less parameters.

By collecting personal information, the real weights of the users can be acquired. This could be reached through extraction from usage statistics (e.g., average waiting time for the bus) or by letting the user choose the value of the weight parameter, which is adapted during real usage (e.g., number of daily trips). As a consequence, the belongingness to a user group can be analyzed (e.g., the certain user likes biking more than the average of their user group). Finally, case studies could be carried out that would include the logging of user trips and comparing the activity chains of the original and optimized version.

\section{Conclusions}

In this paper, a model with a set of parameters was introduced and grouped into classification parameters (to classify users into user groups) and optimization parameters (to provide utilities to the optimization algorithm). The parameters were connected to the user, the chosen transportation mode, or to the location type of the activity. Aggregated weights were assigned to the optimization parameters, which represent the preferences of the users. A utility function was also elaborated to provide input for the optimization algorithm about the preferences of the user. As a conclusion, it was observed that some parameters were easy to include in the optimization algorithm (e.g., time), but some were hard to quantify or collect. In order to realize the optimization framework in real circumstances, a huge amount of external information is required to feed the model. 
Funding: The research reported in this paper was supported by the BME Artificial Intelligence FIKP grant of EMMI (BME FIKP-MI/SC).

Acknowledgments: The elaborated method is based on the author's previous works with his supervisor during his PhD studies. Therefore, the author is grateful for the support and ideas of his supervisor.

Conflicts of Interest: The authors declare no conflict of interest.

\section{References}

1. Bhat, C.R.; Singh, S.K. A comprehensive daily activity-travel generation model system for workers. Transp. Res. Part A Policy Pract. 2000, 34, 1-22. [CrossRef]

2. Wen, C.-H.; Koppelman, F.S. A conceptual and methdological framework for the generation of activity-travel patterns. Transportation 2000, 27, 5-23. [CrossRef]

3. Bowman, J.L.; Ben-Akiva, M.E. Activity-based disaggregate travel demand model system with activity schedules. Transp. Res. Part A Policy Pract. 2001, 35, 1-28. [CrossRef]

4. Islam, M.T.; Habib, K.M.N. Unraveling the relationship between trip chaining and mode choice: Evidence from a multi-week travel diary. Transp. Plan. Technol. 2012, 35, 409-426. [CrossRef]

5. McGuckin, N.; Murakami, E. Examining Trip-Chaining Behavior: Comparison of Travel by Men and Women. Transp. Res. Rec. J. Transp. Res. Board 1999, 1693, 79-85. [CrossRef]

6. Subbarao, S.S.V.; Krishna Rao, K.V. Trip chaining behavior in developing countries: A study of Mumbai Metropolitan Region, India. Eur. Transp. 2013, 53, 1-7.

7. Golob, T.F.; Hensher, D.A. The trip chaining activity of Sydney residents: A cross-section assessment by age group with a focus on seniors. J. Transp. Geogr. 2007, 15, 298-312. [CrossRef]

8. Kotoula, K.; Sialdas, A.; Botzoris, G.; Chaniotakis, E.; Grau, J.M. Exploring the Effects of University Campus Decentralization to Students' Mode Choice. Period. Polytech. Transp. Eng. 2018, 46, 207-214. [CrossRef]

9. Mazzulla, G. An activity-based system of models for student mobility simulation. Eur. Transp. Res. Rev. 2009, 1, 163-174. [CrossRef]

10. Pronello, C.; Camusso, C. Travellers' profiles definition using statistical multivariate analysis of attitudinal variables. J. Transp. Geogr. 2011, 19, 1294-1308. [CrossRef]

11. Prillwitz, J.; Barr, S. Moving towards sustainability? Mobility styles, attitudes and individual travel behavior. J. Transp. Geogr. 2011, 19, 1590-1600. [CrossRef]

12. Haustein, S.; Hunecke, M. Identifying target groups for environmentally sustainable transport: Assessment of different segmentation approaches. Curr. Opin. Environ. Sustain. 2013, 5, 197-204. [CrossRef]

13. Timmermans, H.J.; Van Der Waerden, P.; Alves, M.; Polak, J.W.; Ellis, S.; Harvey, A.S.; Kurose, S.; Zandee, R. Spatial context and the complexity of daily travel patterns: An international comparison. J. Transp. Geogr. 2003, 11, 37-46. [CrossRef]

14. Liao, F.; Arentze, T.A.; Timmermans, H. Incorporating space-time constraints and activity-travel time profiles in a multi-state supernetwork approach to individual activity-travel scheduling. Transp. Res. Part B Methodol. 2013, 55, 41-58. [CrossRef]

15. Buliung, R.N.; Roorda, M.J.; Remmel, T.K. Exploring spatial variety in patterns of activity-travel behaviour: Initial results from the Toronto Travel-Activity Panel Survey (TTAPS). Transportation 2008, 35, 697-722. [CrossRef]

16. Balaji, M.; Santhanakrishnan, S.; Dinesh, S.N. An Application of Analytic Hierarchy Process in Vehicle Routing Problem. Period. Polytech. Transp. Eng. 2019, 47, 196-205. [CrossRef]

17. Hafezi, M.H.; Liu, K.; Millward, H. Learning Daily Activity Sequences of Population Groups using Random Forest Theory. Transp. Res. Rec. J. Transp. Res. Board 2018, 2672, 194-207. [CrossRef]

18. Kang, J.E.; Recker, W.W. The location selection problem for the household activity pattern problem. Transp. Res. Part B Methodol. 2013, 55, 75-97. [CrossRef]

19. Hilgert, T.; Kagerbauer, M.; Schuster, T.; Becker, C. Optimization of Individual Travel Behavior through Customized Mobility Services and their Effects on Travel Demand and Transportation Systems. Transp. Res. Procedia 2016, 19, 58-69. [CrossRef]

20. Juhasz, M.; Mátrai, T.; Kerényi, L.S. Changes in Travel Demand in Budapest during the Last 10 Years. Transp. Res. Procedia 2014, 1, 154-164. [CrossRef]

21. Prelipcean, A.C.; Gidofalvi, G.; Susilo, Y.C.P.A. Comparative framework for activity-travel diary collection systems. In Proceedings of the 2015 International Conference on Models and Technologies for Intelligent Transportation Systems (MT-ITS), Budapest, Hungary, 3-5 June 2015; pp. 251-258. 
22. Duleba, S.; Mishina, T.; Shimazaki, Y. A dynamic analysis on public bus transport's supply quality by using ahp. Transportation 2012, 27, 268-275. [CrossRef]

23. Sierpiński, G.; Staniek, M.; Celiński, I. Travel Behavior Profiling Using a Trip Planner. Transp. Res. Procedia 2016, 14, 1743-1752. [CrossRef]

24. Lawton, T.K. Activity and time use data for activity-based forecasting. In Proceedings of the Activity-Based Travel Forecasting Conference, New Orleans, LA, USA, 2-5 June 1996; pp. 103-118.

25. Frignani, M.Z.; Auld, J.A.K.C.; Nelson, P. Urban Travel Route and Activity Choice Survey: Internet-Based Prompted-Recall Activity Travel Survey Using Global Positioning System Data. Transp. Res. Rec. J. Transp. Res. Board 2010, 2183, 19-28. [CrossRef]

26. Arentze, T.; Kemperman, A.; Aksenov, P. Estimating a latent-class user model for travel recommender systems. Inf. Technol. Tour. 2018, 19, 61-82. [CrossRef]

27. Arentze, T.A. Adaptive Personalized Travel Information Systems: A Bayesian Method to Learn Users' Personal Preferences in Multimodal Transport Networks. IEEE Trans. Intell. Transp. Syst. 2013, 14, 1957-1966. [CrossRef]

28. Nijland, L.; Arentze, T.; Timmermans, H. Incorporating planned activities and events in a dynamic multi-day activity agenda generator. Transportation 2012, 39, 791-806. [CrossRef]

29. Miller, E.J.; Roorda, M.J. Prototype Model of Household Activity-Travel Scheduling. Transp. Res. Rec. J. Transp. Res. Board 2003, 1831, 114-121. [CrossRef]

30. Chowdhury, T.; Scott, D.M. Role of the built environment on trip-chaining behavior: An investigation of workers and non-workers in Halifax, Nova Scotia. Transportation 2018, 47, 737-761. [CrossRef]

31. Dib, O.; Manier, M.-A.; Caminada, A. Memetic Algorithm for Computing Shortest Paths in Multimodal Transportation Networks. Transp. Res. Procedia 2015, 10, 745-755. [CrossRef]

32. Ghiani, G.; Manni, E.; Thomas, B.W. A Comparison of Anticipatory Algorithms for the Dynamic and Stochastic Traveling Salesman Problem. Transp. Sci. 2012, 46, 374-387. [CrossRef]

33. Nuzzolo, A.; Comi, A. Individual utility-based path suggestions in transit trip planners. IET Intell. Transp. Syst. 2016, 10, 219-226. [CrossRef]

34. Västberg, O.B.; Karlström, A.; Jonsson, D.; Sundberg, M. A Dynamic Discrete Choice Activity-Based Travel Demand Model. Transp. Sci. 2019, 54,1-21. [CrossRef]

35. Pougala, J.; Hillel, T.; Bierlaire, M. Scheduling of daily activities: An optimization approach. In Proceedings of the 20th Swiss Transport Research Conference (STRC), Lausanne, Switzerland, 13-14 May 2020.

36. Malik, S.; Kim, D. Optimal Travel Route Recommendation Mechanism Based on Neural Networks and Particle Swarm Optimization for Efficient Tourism Using Tourist Vehicular Data. Sustainability 2019, 11, 3357. [CrossRef]

37. Charypar, D.; Nagel, K. Generating complete all-day activity plans with genetic algorithms. Transportation 2005, 32, 369-397. [CrossRef]

38. Saharidis, G.K.D.; Rizopoulos, D.; Fragkogios, A.; Chatzigeorgiou, C. A hybrid approach to the problem of journey planning with the use of mathematical programming and modern techniques. Transp. Res. Procedia 2017, 24, 401-409. [CrossRef]

39. Aifadopoulou, G.; Ziliaskopoulos, A.; Chrisohoou, E. Multiobjective Optimum Path Algorithm for Passenger Pretrip Planning in Multimodal Transportation Networks. Transp. Res. Rec. J. Transp. Res. Board 2007, 2032, 26-34. [CrossRef]

40. Delling, D.; Dibbelt, J.; Pajor, T.; Wagner, D.; Werneck, R.F. Computing Multimodal Journeys in Practice. Comput. Vis. 2013, 7933, 260-271. [CrossRef]

41. Freisleben, B.; Merz, P. A genetic local search algorithm for solving symmetric and asymmetric traveling salesman problems. In Proceedings of the IEEE International Conference on Evolutionary Computation, Nagoya, Japan, 20-22 May 1996; pp. 616-621.

42. Nygard, K.E.; Yang, C.H. Genetic Algorithms for the Traveling Salesman Problem with Time Windows. In Computer Science and Operations Research; Elsevier: Amsterdam, The Netherlands, 1992; pp. 411-423. [CrossRef]

43. Hwang, H.-S. An improved model for vehicle routing problem with time constraint based on genetic algorithm. Comput. Ind. Eng. 2002, 42, 361-369. [CrossRef]

44. Archetti, C.; Feillet, D.; Gendreau, M.; Speranza, M.G. Complexity of the VRP and SDVRP. Transp. Res. Part C Emerg. Technol. 2011, 19, 741-750. [CrossRef]

(C) 2020 by the author. Licensee MDPI, Basel, Switzerland. This article is an open access article distributed under the terms and conditions of the Creative Commons Attribution (CC BY) license (http://creativecommons.org/licenses/by/4.0/). 